\title{
Angiopoietin-2: A Key to Understanding Sepsis and Its Pulmonary Sequelae?
}

\author{
Ji Young Lee ${ }^{1,2,3 *}$ and Edmund J. Miller ${ }^{1,2,4}$ \\ ${ }^{1}$ The Elmezzi Graduate School of Molecular Medicine, Manhasset, NY, USA \\ ${ }^{2}$ Center for Heart and Lung Research, The Feinstein Institute for Medical Research, Manhasset, NY, USA \\ ${ }^{3}$ Department of Pulmonary Critical Care Medicine, University of South Alabama, Mobile, AL, USA \\ ${ }^{4}$ Medicine and Molecular Medicine, Hofstra North Shore-LIJ Medical School Hempstead, NY, USA
}

\begin{abstract}
Sepsis remains a major cause of morbidity and mortality especially in the older individual. In the US alone, sepsis occurs in approximately 750,000 individuals per year and ranks as the tenth leading cause of death. A major complication of sepsis is organ failure, with the lung being one of the first organs to fail. Moreover, sepsis is the most common risk factor for Acute Lung Injury (ALI) and approximately $50 \%$ of individuals with sepsis subsequently develop ALI. Despite its importance, the pathophysiology of sepsis remains unclear. Angiopoietin-2 (Ang-2) is a component of pathways involved in endothelial survival and maintenance of a quiescent state of the vascular system. The functional significance of Ang-2 remains to be fully elucidated, but the evidence thus far suggests that it may be key to a better understanding of the vascular dysfunction and associated organ failure that are so devastating in sepsis. However, the assessment of the cellular release of Ang-2 is not without difficulty. In this brief review, we discuss the relevance of Ang-2 to the endothelial dysfunction associated with the severe inflammatory response in sepsis, and why Ang-2 may not be just a biomarker, but may play a critical role in the pathology. In addition, we discuss some of the reasons why particular sepsis models may present confusing data with respect to Ang-2 involvement.
\end{abstract}

\section{Introduction}

Sepsis has been recognized since ancient times [1], and the gross pathology of pulmonary edema in the absence of cardiac insufficiency was described in the first quarter of the $19^{\text {th }}$ century [2]. Yet, sepsis and Acute Lung Injury (ALI) remain major sources of morbidity and mortality especially in the older individual [3-6]. Indeed, approximately $50 \%$ of individuals with severe sepsis develop ALI $[7,8]$. While there have been significant advances in the treatment of both sepsis and ALI, particularly in the areas of antimicrobial $[9,10]$, resuscitative [11-13], and ventilation therapies [14,15], the disappointing lack of major advances in therapeutic interventions, highlights the need for a better understanding of the molecular mechanisms underlying these conditions. Here we examine the altered pulmonary endothelial activity that results in altered vascular integrity and hemodynamic instability. Angiopoietin 2 (Ang-2) [16] is a naturally occurring ligand for the endothelial receptor tyrosine kinase-2(Tie-2) [17]. In view of the significant correlations of Ang-2 levels with clinical features of sepsis [18-25], and the characteristic of the Ang/Tie system having control over vascular system homeostasis [18,26,27], this review will focus on the importance of Ang-2 in the better understanding of sepsis/ALI pathophysiology.

\section{Sepsis and Acute Lung Injury}

Sepsis is a progressive, injurious, systemic response of the host to an infection [28]. In the initial response to a local infection, the interaction with bacterial toxins can drive proximal cells to release several mediators involved in the proinflammatory response [29-31]. However, the excessive, unrestrained release of these mediators can result in the development of an overwhelming systemic response, characteristic of sepsis, leading ultimately to cardiovascular collapse $[32,33]$. A common feature of both sepsis and ALI is the development of increasing vascular leakage leading to extravascular fluid accumulation, intravascular volume depletion, circulatory and respiratory failure [3436].The failure is due in part to the unresolved lung inflammation that results in loss of endothelial barrier integrity. These changes lead to an imbalance between an increased oxygen demand as a result of increased cellular metabolism, and decreased oxygen transport, resulting from myocardial depression, and inefficient oxygen extraction due to changes in the peripheral microvasculature $[37,38]$. The respiratory failure tends to be severe enough to require ventilatory support in approximately $85 \%$ of cases [39]. Furthermore, approximately fifty percent of the septic individuals requiring ventilatory support progress to the acute respiratory distress syndrome [39]. The mortality associated with ALI is greater than $38 \%$, and the mortality rate greatly increases as a function of age [5].

Death in sepsis most likely results from the collective burden of the sequential failures of organ systems [34,40]. Although the starting points are the same, simple local infection and complicated sepsis have very different disease courses. Most simple local infections can be eradicated by normal functions of the immune system and sometimes with the help of anti-bacterial [41-43], -viral [44-46], or -fungal [47-49] agents or thermal interventions [50]. During the disease course, even after etiologic organisms are controlled, it still takes time until inflammation resolves. For this process to be successful, an optimal environment of proper oxygenation and circulation by an intact vasculature is critical. If it fails, the healing process can be delayed or complicated as can be seen in patients with diabetes or peripheral vascular disease who often have chronic non-healing wounds $[51,52]$. In severe sepsis, the same principles apply because of the fundamental problem of the vascular system failure. Systemic inflammation or generalized vascular inflammation can result in vascular dysfunction. In inflamed dysfunctional vessels, activated Endothelial Cells (ECs) secrete a variety of cytokines, recruit immune cells and activate coagulation cascades.

*Corresponding author: Ji Young Lee, MD, Department of Pulmonary Critica Care Medicine, University of South Alabama, USA, Tel: 251-471-7914; E-mail: jiyounglee98@gmail.com

Received December 27, 2013; Accepted February 06, 2014; Published February 10,2014

Citation: Lee JY, Miller EJ (2014) Angiopoietin-2: A Key to Understanding Sepsis and Its Pulmonary Sequelae? J Pulm Respir Med 4: 172. doi:10.4172/2161105X.1000172

Copyright: ( 2014 Lee JY, et al. This is an open-access article distributed under the terms of the Creative Commons Attribution License, which permits unrestricted use, distribution, and reproduction in any medium, provided the original author and source are credited. 
Most importantly, the vessels are highly permeable. Leaky vessels with decreased tone not only destabilize the overall hemodynamics, but also create increased interstitial spaces making oxygen and nutrient supply to the target tissues difficult. Considering the vascular system as one big web of highways to every single cell in the body, it is not surprising that any organ can be affected and eventually fail in sepsis, in a state of global vascular inflammation and dysfunction. This is one of the reasons why it is difficult to predict the efficacy of any medication given in sepsis. In short, sepsis is a life-threatening disease because it is a state of systemic vascular inflammation. It can involve any organ that gets oxygen supply by the vascular system which means all organs in the body are potentially vulnerable in sepsis. Vascular inflammation and dysfunction makes the healing process fundamentally impaired, triggering a vicious cycle of worsening inflammation, more organ damage and dysfunction, ultimately resulting in shock and multiple organ failure.

There is considerable evidence that microvascular dysfunction is a critical event in sepsis [53-55]. A major function of the microcirculation is to provide appropriate oxygen delivery for parenchymal cell requirements in each organ. In addition, this network of small blood vessels plays roles in modulation of inflammation and coagulation. In the healthy state, the microvasculature responds to changes in both blood flow and metabolic demands. However in sepsis these functions, which are predominantly controlled by endothelial cells [56], become dysfunctional [57], and there is evidence that the endothelium is predominantly a target rather than a source of systemic inflammation [58]. Furthermore, data from animal and human studies suggest that improving endothelial function, and in particular reducing endothelial barrier dysfunction, can significantly improve sepsis outcome $[59,60]$.

In view of the critical importance of altered endothelial barrier function during severe sepsis, there is great interest in the factors that could mediate these changes. In particular, interest has been drawn to the angiopoietin-Tie2 system, a signaling pathway involved in the control of microvascular permeability $[61,62]$.

\section{Angiopoietin-2}

Ang-2, a molecule implicated in the pathogenesis of critical illness $[63,64]$, is a member of the Ang/Tie (angiopoietin/tyrosine kinase with immunoglobulin-like and EGF-like domains) system. The system consists of four ligands, Ang-1, 2, 3 and 4 and two receptors, Tie-1 and 2. Ang-1 and Ang-2 (both of which bind to Tie-2 [16,65-67] are believed to be more clinically relevant and better studied than others. Ang- 2 [16] was originally identified from its homology to the angiogenic factor Angiopoietin-1 (Ang-1), with which it shares significant amino acid identity $[16,68]$. Although it was initially recognized for its antiangiogenic properties, over the intervening years much emphasis has focused on its role in modulating vascular permeability, particularly in inflammatory lung disease [69], sepsis [19,26,70-72] and acute lung injury $[21,24,25,73]$. Furthermore, the simplistic assessment that Ang- 1 is a Tie- 2 receptor agonist that phosphorylates and activates downstream pathways to promote EC survival and maintenance of the quiescent state of the vascular system; and that Ang-2 antagonizes Ang-1 activity to increase apoptosis, inflammation and subsequently endothelial permeability, is somewhat limited. Recent studies suggest that Ang-2 has complex, context-dependent variable actions which remain somewhat ill-defined [26,27]. Figure 1 shows the effects of Ang/ Tie-2 interactions on endothelial permeability.

\section{Angiopoietin-2 and the Weibel-Palade Body}

Ang-2 is synthesized and stored, primarily, in endothelial cellspecific organelles (known as Weibel-Palade bodies (WPB)) which can, in the presence of various inflammatory stimuli, be released rapidly by exocytosis [74,75]. The dynamics and plasticity of WPB have been reviewed previously by Rondaij et al. [74]. The WPB also contain other proteins including von Willebrand factor (VWF) [76], endothelin [77], interleukin-8 [78], p-selectin [79], and tissue-type plasminogen

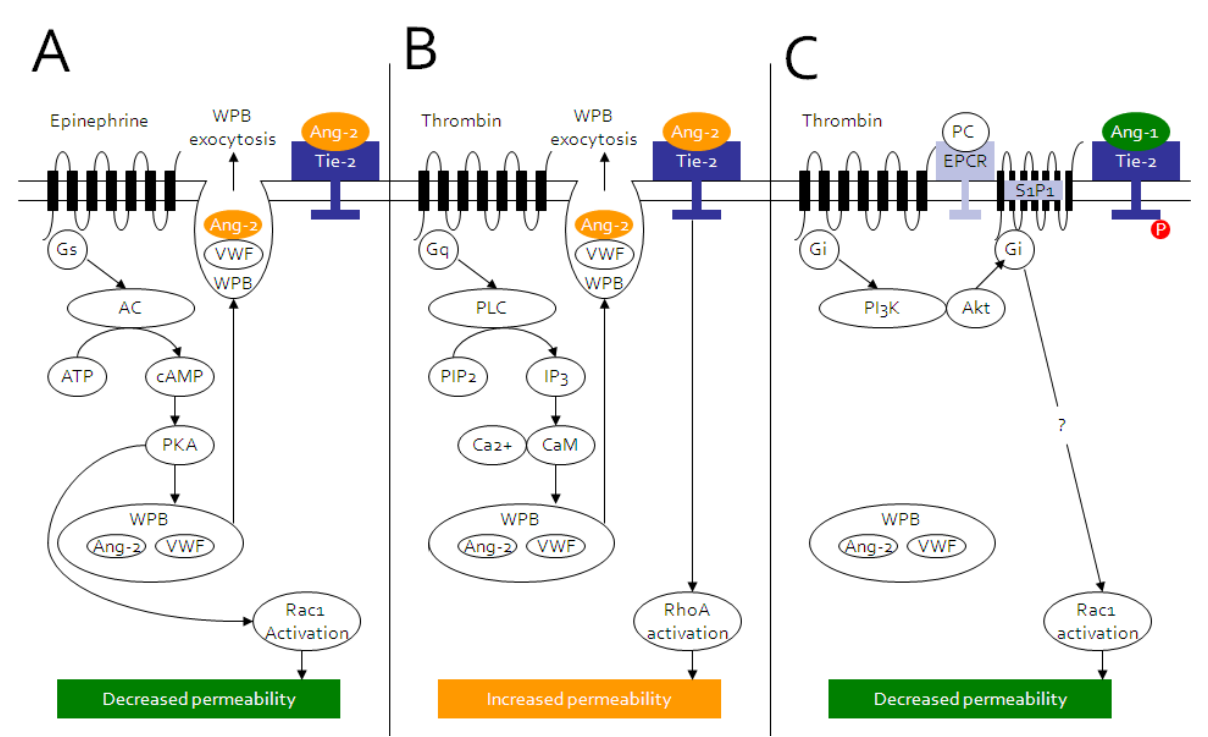

Figure 1: Permeability change by induced secretion of Ang-2: opposing effects depending on different secretary agonists.

A. Although epinephrine induces WBP exocytosis, thus Ang-2 secretion, it rather decreases EC permeability by a direct effect on Rac1 activation mediated by cAMPPKA pathway. B. Thrombin induces increased EC permeability by PLC-Ca ${ }^{2+}$ mediated Ang-2 exocytosis which results in RhoA activation. C. Thrombin, in the presence of protein $\mathrm{C}$ in EPCR, induces decreased EC permeability mediated by Gi protein-PI3K-Akt and/or transactivation of S1P1 and by increasing expression of Ang-1 Tie-2, subsequently resulting in Rac1 activation. Gs, Gq, Gi, G protein -coupled receptors; AC, adenylyl cyclase; PKA, protein kinase A; PLC, phospholipase C; PIP2, phosphatidylinositol biphosphate; IP3, inositol $(1,4,5)$ triphosphate; CaM, calmodulin; EPCR, endothelial protein C receptor; S1P1, sphingosine 1-phosphate receptor; PI3k, phosphatidylinositol 3-kinase; Akt [74,141]. 
activator (t-PA) [80]. However, many of the components of the WPB are not unique to this organelle and are also stored elsewhere in the cell $[81,82]$. Therefore while many of the endothelial cell proteins stored in the WPB may be secreted together from endothelial cells by both constitutive and regulated secretion [74], their release may also be induced separately [83]. The situation is further complicated by the substantial heterogeneity of endothelial cells from different sources, even from a single organ [84-86]. Thus, the structure and function of the microcirculation differs between organs and depends upon the function of that organ [87]. Similarly the endothelial cells that line the vessels are not homogeneous throughout the cardiovasculature. There is heterogeneity between micro- and macro-vascular endothelial cells as well as between microvascular endothelial cells from different vascular beds [88]. They are morphologically different (continuous, fenestrated, and discontinuous) and have structural differences related to macromolecular transport between blood and tissues [85]. This is perhaps exemplified by the presence or absence of WPB [89].

Understanding WPB exocytosis-mediated Ang-2 secretion is very important in studying sepsis for many reasons. First, it is known that various bacterial compounds induce WPB exocytosis, so it is highly likely that in the septic state there is a high degree of WPB activation [90,91]. Second, in addition to Ang-2, WPB contains many molecules involved in inflammation and coagulation pathways including VWF, P-selectin and t-PA [74,92], although the effects of these molecules are not limited to either inflammation or coagulation. For example, VWF is an important mediator of coagulation, but it is also known to promote leukocyte extravasation [93]. Thus, uncontrolled activation of the inflammatory and coagulant pathways associated with sepsis could be explained by endothelial activation and rapid deposition of WPB contents into the blood stream.

Since the storage and release of Ang-2 is complex, there are many issues to be considered in regard to Ang-2 activity, including release, plasma accumulation, and the presence of other mediators. Each of these areas has been studied, and the data obtained may sometimes appear conflicting. Some of the studies are outlined below, and some limitations of the types of studies discussed.

\section{Clinical Studies}

Of the many markers of endothelial activation known to be elevated in sepsis [94,95] Ang-2 is a useful marker of organ dysfunction and mortality in severe sepsis [72,96-98]. In addition, four studies illustrate the possible importance of Ang-2 as a marker in sepsis. First, a prospective clinical study of 61 septic patients found Ang2 concentrations to have a positive linear relationship with plasma TNF- $\alpha$ and IL- 6 concentrations as well as the severity of sepsis assessed by Acute Physiology and Chronic Health Evaluation (APACHE) II and Sequential Organ Failure Assessment (SOFA) scores [99] . Second, in a study of 124 individuals, Ang-2 was elevated in sepsis and correlated with plasma IL- 6 concentration but not TNF- $\alpha$ which was below the assay lower limit of detection in most cases [100]. In this study, Ang2 correlated with organ failure. The study also revealed increased Ang- 2 concentrations to be related to decreased reactive hyperaemiaperipheral arterial tonometry (RH-PAT), a measure of nitric oxide bioavalability. The authors suggested that the decreased bioavalability of nitric oxide may be directly involved in the increased, extracellular accumulation of Ang-2. Third, in 9 recent randomized trial of 931 patients with ALI, compared to VWF, Ang-2 had a differential prognostic value for mortality depending on the infection status and the levels were affected by the type of fluid therapy suggesting its specificity as a marker of overall vascular status and sepsis pathophysiology [23].
The fourth report describes a prospective, observational study carried out at a tertiary care center pediatric intensive care unit [101]. The authors of the study measured both plasma Ang-1 and Ang- 2 and showed that the Ang-2/1 ratio was elevated in the first three days of sepsis, with the peak at day 2 .

In spite of the close correlation between disease severity and serum level, whether Ang-2 is a marker of disease or one of the important etiologic factors in disease progression, remains unclear. In addition, although increased levels can give clues to possible mediators of the disease, they do not necessarily explain the mechanisms involved. Thus, if Ang- 2 is a mere marker of endothelial dysfunction or a critical factor to the disease pathogenesis remains to be fully elucidated.

\section{In vivo Animal Studies}

In vivo studies reveal data consistent with the earlier concept of Ang1 and Ang-2 as simple agonist and antagonist, respectively. To evaluate the interactions, the expression of Ang-1 and -2 has been manipulated in murine models. These studies show that Ang-1-overexpressing mice are resistant to vascular leakage caused by inflammatory agents [102], while Ang-2 knockout mice have impaired leukocyte adhesion to activated endothelial cells in response to TNF- $\alpha$ [103]. In addition, mice genetically deficient in Ang-2 showed decreased vascular leakage in response to histamine, bradykinin or VEGF administration [104]. Consistent with these findings, Ang-2 heterozygous mice develop less vascular inflammation, organ dysfunction and superior survival in cecal ligation and puncture sepsis model [105]. In addition, overexpression of Ang-2 in mice resulted in a sepsis-like phenotype including hyperpermeability, hypercirculatory hypotension, cardiac hypertrophy, and fibrosis which are prevented by increasing Ang-1 or inhibiting Ang-2 [106]. Other investigators have taken the approach of evaluating the effects of injecting exogenous Ang-2. Local injection of recombinant Ang-2 induces rapid edema formation in the mouse paw in a dose-dependent manner peaking at $30 \mathrm{~min}$ and resolving by $4 \mathrm{~h}$ [107]. However, systemic administration of Ang-2 induces vascular hyper-permeability and pulmonary congestion within 3 hours which progresses over 48 hours in a dose dependent manner [108]. Furthermore, in a mouse model, blocking Ang-2 exocytosis is associated with improved pulmonary function following Gram-positive challenge [109]. Lomas-Neira et al. [110] have also investigated a "two-hit" model of indirect-acute lung injury induced by hemorrhagic shock and sepsis [110]. The authors showed that Ang-2 was elevated in this model, and that direct interactions between neutrophils and the endothelium significantly contributed to the extracellular accumulation of Ang-2. Importantly, they found that suppression of Ang- 2 activity by injecting the mice intravenously with an siRNA targeting Ang-2 production, decreased inflammatory lung injury, neutrophil recruitment, and the plasma concentrations of both IL-6 and TNFa.

Based on these results, elevated Ang-2 levels shown in clinical studies are consistent with Ang-2 as a pro-inflammatory and permeability inducing factor. However, some in vitro studies raise questions challenging this concept.

\section{In vitro studies}

VWF and Ang-2 are co-localized within WPB and are depleted concurrently within 15 min upon uric acid stimulation of HUVEC [111]. However, peptidoglycan, a component of the bacterial cell wall, induces secretion of VWF selectively, and not that of Ang-2 [112]. This implies that for each specific stimulus of WPB exocytosis, there may be different molecules co-secreted which could affect the final action. 
Second, although t-PA is known to be stored in WPB, at least one study showed that VWF and t-PA are stored separately, VWF in large tubular WPB and t-PA in smaller discrete punctate structures [92]. The authors demonstrated many different sizes of granules going through exocytosis along with WPB with variable thresholds of activation in response to stimulation. WPB can also be exocytosed without exogenous stimulation [113]. Other studies show that there is constitutive release of Ang-2 into cell culture medium even in the absence of defined stimulation $[114,115]$. Taken together, the data suggest that it is highly possible that Ang-2 is stored not only in WPB but also in other secretary granules that can have a variety mechanisms of release. One interesting finding, revealed by electrophysiological studies of WPB exocytosis, is that calcium induced exocytosis is accompanied by active endocytosis, especially after an initial rapid exocytosis phase [113]. If endocytosis overrides exocytosis, this may explain the phenomenon of certain situations where there is a decrease, rather than an increase, in extracellular Ang-2 level in culture medium after stimulation [114].

\section{Permeability Change by Manipulation of Tie-2 Receptor}

Transfection of endothelial cells with Tie-2 specific siRNA significantly increases the permeability of the EC layer $[108,115]$. This suggests that Ang-1 has a protective effect on cell layer permeability. However, it does not necessarily offer any useful information regarding an Ang-2 effect on cell permeability, since Ang-2 effects on Tie-2 receptor are variable and context-dependent [116].

Ang-2 is synthesized and secreted by ECs, and acts on Tie- 2 in an autocrine manner [16,117]. On the other hand, Ang- 1 , which is believed to occupy the same receptor, and result in phosphorylation of Tie-2 when vessels are in a quiescent state, is synthesized and secreted by pericytes and smooth muscle cells. Studies of the effects of on Tie-2 receptor phosphorylation indicate that Ang-1 alone can induce Tie-2 phosphorylation at 15 and $30 \mathrm{~min}$, and that Ang-2 blocks this response. However, Ang-2 alone does not change the Tie-2 phosphorylation state [114]. Other studies have shown that high concentrations of Ang-2 itself can lead to Tie-2 phosphorylation. Additionally, Ang-2 initiation of the pathways activated downstream of Tie- 2 phosphorylation are slightly different from those activated by Ang-1 [118]. Overall, the data suggest that Ang-2 has an antagonistic effect against Ang-1-Tie-2 interaction rather than against the Tie-2 receptor itself, and that Tie-2 phosphorylation status is not a single confirmatory marker to show the activity of Ang-2.

\section{Permeability Changes Induced by Direct Addition of Recombinant Ang-2}

For reasons similar to those discussed previously, studies of the effect of recombinant Ang-2 on permeability are not simple to interpret. One study showed that addition of neither Ang- 2 nor Ang- 1 affects the basal passage of Horseradish Peroxidase (HRP) or Transepithelial Electrical Resistance (TEER) at concentrations ranging from 5 to $400 \mathrm{ng} / \mathrm{ml}$ at $30 \mathrm{~min}$ to 5 hours in human pulmonary microvascular endothelial cells (HPMVEC) [114]. In this study the authors observed that Ang-1 enhanced the basal activity of Racl and Ang-2 had a statistically nonsignificant opposite trend to reduce the activity. However, a study by Parikh et al. [108] showed recombinant Ang-2 (100ng/ml) induces thick actin stress fibers and intercellular gap formation and increases permeability measured by FITC-labeled albumin passage in human microvascular endothelial cells (HMVECs, from neonatal dermis) [108]. Although the results from the second study may seem to be more reflective of the in vivo and clinical situation, considering the cell type used, the study of van der Heijden may be more relevant to sepsis pathophysiology (Figure 2).

\section{Limitations of in vitro Systems for the Study of Ang-2}

Endothelial cells are known to be highly heterogeneous $[117,119]$. Even among the same cell types, WPB content depends on the passage number and the state of confluence [113]. WPB may not be observed in newly plated endothelial cells until after at least $24 \mathrm{~h}$. Thereafter, the numbers of WPB per cell may increase to reach a steady level by 48 $72 \mathrm{~h}$. Hence, even if the cells reach confluence, but the culture time is not long enough for the cells to develop mature WPB (to produce a burst reaction in response to stimulus), the same stimulus could induce different results. In addition, isolated EC culture systems are not ideal to study the Ang/Tie-2 system because there are no pericytes or smooth muscle cells which are the physiologic sources of Ang-1 and natural environments of the system. It is known that ECs and mural

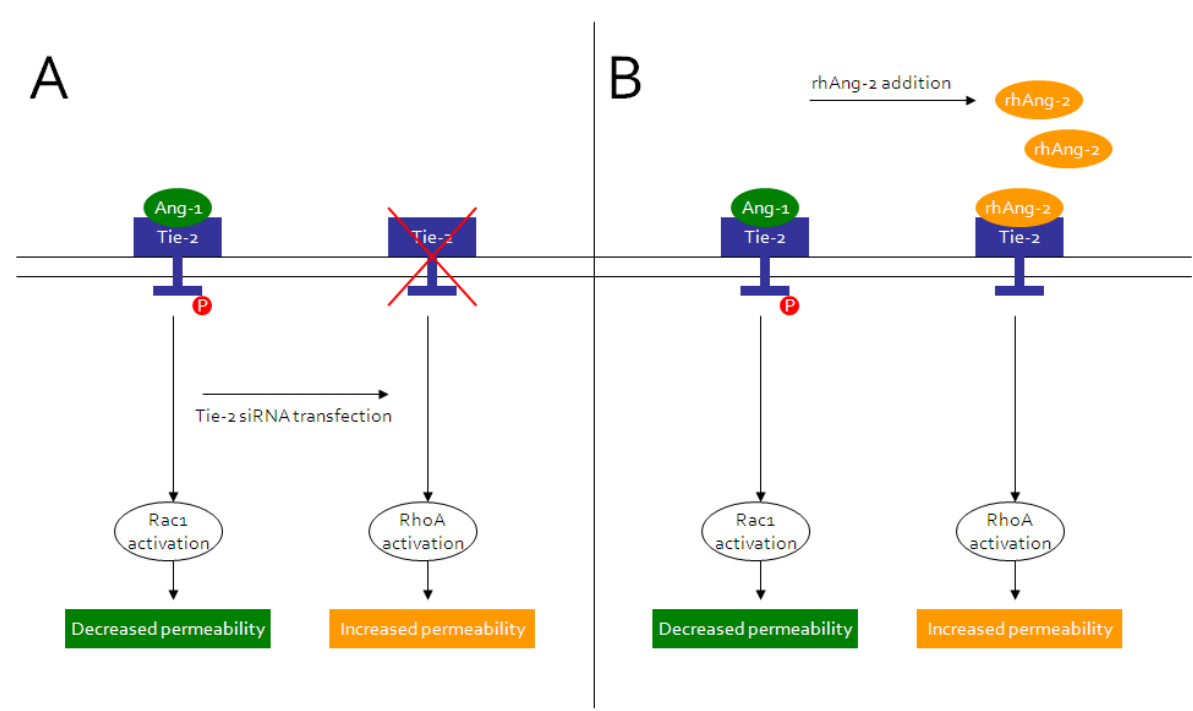

Figure 2: Manipulating endothelial permeability.

A. Ang-1 has a protective effect on cell layer permeability. siRNA transfection of Tie-2 has an opposite effect on permeability. B. Direct addition of recombinant Ang-2 induces increased permeability showing the antagonistic effect of Ang-2 on Ang-1-Tie-2 induced protective effect on permeability. 
cells are highly interactive [120-123]. As a result, in monocultures, critical factors, including Ang-1, are missing, which could confound the assessment of Ang-2 effects. Thus, it is reasonable to consider co-cultures or pre-treatment with Ang-1 for in vitro studies of Ang/ Tie-2 system. In addition, ECs are known to communicate with other hematopoietic cells[124], and there is evidence suggesting that EC Ang2 may recruit Tie-2 positive monocytes to inflammatory sites [125]. This being the case, it is highly likely that in sepsis ECs actively communicate with other inflammatory cells. Thus, studying EC-inflammatory cell communication could also give new insights into the role of the Ang/ Tie-2 system.

There are many artificial environmental factors that can potentially affect study results of in vitro culture systems. For example, it is known that WPB exocytosis is affected by $\mathrm{pH}$ [126] and Ang-2 expression is up regulated by hyperoxia [127]. To complicate the situation further, in vitro culture conditions, do not reflect the physiological conditions and the generally accepted culture terminology can be misleading. For example, the terms, "normoxic" and "hypoxic" conditions used in cell culture [128] may not be representative of the in vivo situations. Cell cultures are conventionally maintained with the oxygen level equivalent to that of room air (approx 20\% oxygen). While this is normally referred to as "normoxic", it is not the physiologic environment that cells would experience in vivo. In addition, the oxygen concentration at the cellular level in static in vitro culture changes greatly depending on the amount of culture medium and the cell number [129-134]. Since hypoxia is a known triggering factor of WPB exocytosis [135] and Ang2 dynamics are affected by both hypoxia and hyperoxia, the effect of significantly different oxygen levels generated by slight differences in cell culture environment should not be ignored. In addition, there are other unanswered fundamental questions in cell culture systems. There is consensus that the passage number of primary cells should be kept low so that they are studied before possible changes in phenotype [136]. However, during the processes of cell isolation and freeze- thawing, the cells are subject to considerable stress. The rate of cell replication, intracellular pathway activation, secretion of cytokines, and the expression of the surface molecules can be altered as a result of this stress [137-140]. Thus, it is often difficult to assess which cell phenotype best reflects the in vivo situation. Clearly, in vitro cultures only model the in vivo situation. However, efforts to isolate and minimize confounding factors are essential especially in a system as complicated, dynamic, and inter-dependent as Ang/Tie-2-WPB. As in many systems, due to dynamic interactions, no one molecule can be examined separately and efforts should be made to compensate for the deficient conditions.

\section{Conclusion}

Multiple clinical studies have consistently shown close correlation between Ang-2 level and sepsis severity and its pulmonary sequelae. Thus, Ang-2 is most likely an important mediator, or at least a clear marker of disease severity, in sepsis pathophysiology. So far, in vitro studies have shown that Ang-2 induces or enhances EC permeability in a context dependent manner and in vivo and clinical studies suggest Ang-2 as a powerful permeability inducing factor. Taken together, Ang-2 is most likely an effective permeability triggering or enhancing factor only in the presence of other cofactors normally present in physiologic conditions. This makes the mechanisms involved in Ang/ Tie-2 interactions key to a better understanding of the pathogenesis of sepsis and its pulmonary sequelae. It also makes the Ang/Tie-2 system an interesting therapeutic target to improve tissue oxygenation and hemodynamics, and significantly alter the pathological course of sepsis.

\section{References}

1. Funk DJ, Parrillo JE, Kumar A (2009) Sepsis and septic shock: a history. Crit Care Clin 25: 83-101, viii.

2. Laennec $R$ (1829) Treatise on the disease of the chest and on mediate auscultation Third Edition translated by Forbes $\mathrm{J}$ London Pub: $\mathrm{T}$ \& $\mathrm{G}$ Underwood.

3. Wichmann MW, Inthorn D, Andress HJ, Schildberg FW (2000) Incidence and mortality of severe sepsis in surgical intensive care patients: the influence of patient gender on disease process and outcome. Intensive Care Med 26: 167172.

4. Guidet B, Aegerter P, Gauzit R, Meshaka P, Dreyfuss D; CUB-Réa Study Group (2005) Incidence and impact of organ dysfunctions associated with sepsis Chest 127: 942-951.

5. Rubenfeld GD, Caldwell E, Peabody E, Weaver J, Martin DP, et al. (2005) Incidence and outcomes of acute lung injury. N Engl J Med 353: 1685-1693.

6. Angus DC, Linde-Zwirble WT, Lidicker J, Clermont G, Carcillo J, et al. (2001) Epidemiology of severe sepsis in the United States: analysis of incidence outcome, and associated costs of care. Crit Care Med 29: 1303-1310.

7. Hudson LD, Milberg JA, Anardi D, Maunder RJ (1995) Clinical risks for development of the acute respiratory distress syndrome. Am J Respir Crit Care Med 151: 293-301.

8. Sevransky JE, Levy MM, Marini JJ (2004) Mechanical ventilation in sepsisinduced acute lung injury/acute respiratory distress syndrome: an evidencebased review. Crit Care Med 32: S548-553.

9. Kumar A, Roberts D, Wood KE, Light B, Parrillo JE, et al. (2006) Duration of hypotension before initiation of effective antimicrobial therapy is the critical determinant of survival in human septic shock. Crit Care Med 34: 1589-1596.

10. Kumar A, Ellis P, Arabi Y, Roberts D, Light B, et al. (2009) Initiation of inappropriate antimicrobial therapy results in a fivefold reduction of survival in human septic shock. Chest 136:1237-1248.

11. Rivers E, Nguyen B, Havstad S, Ressler J, Muzzin A, et al. (2001) Early goaldirected therapy in the treatment of severe sepsis and septic shock. $\mathrm{N}$ Engl J Med 345: 1368-1377.

12. Micek ST, Roubinian N, Heuring T, Bode M, Williams J, et al. (2006) Beforeafter study of a standardized hospital order set for the management of septic shock. Crit Care Med 34: 2707-2713.

13. Dellinger RP, Levy MM, Rhodes A, Annane D, Gerlach H, et al. (2013) Surviving Sepsis Campaign: international guidelines for management of severe sepsis and septic shock, 2012. Intensive Care Med 39:165-228.

14. The ARDS Network (2000) Ventilation with lower tidal volumes as compared with traditional tidal volumes for acute lung injury and the acute respiratory distress syndrome. The Acute Respiratory Distress Syndrome Network. N Engl J Med 342: 1301-1308.

15. Martin-Loeches I, de Haro C, Dellinger RP, Ferrer R, Phillips GS, et al. (2013) Effectiveness of an inspiratory pressure-limited approach to mechanical ventilation in septic patients. Eur Respir J 41: 157-164.

16. Maisonpierre PC, Suri C, Jones PF, Bartunkova S, Wiegand SJ, et al. (1997) Angiopoietin-2, a natural antagonist for Tie2 that disrupts in vivo angiogenesis. Science 277: 55-60.

17. Witzenbichler B, Maisonpierre PC, Jones P, Yancopoulos GD, Isner JM (1998) Chemotactic properties of angiopoietin-1 and -2 , ligands for the endothelialspecific receptor tyrosine kinase Tie2. J Biol Chem 273: 18514-18521.

18. Scharpfenecker M, Fiedler U, Reiss Y, Augustin HG (2005) The Tie-2 ligand angiopoietin-2 destabilizes quiescent endothelium through an internal autocrine loop mechanism. J Cell Sci 118: 771-780.

19. Gallagher DC, Parikh SM, Balonov K, Miller A, Gautam S, et al. (2008) Circulating angiopoietin 2 correlates with mortality in a surgical population with acute lung injury/adult respiratory distress syndrome. Shock 29: 656-661.

20. Kümpers P, van Meurs M, David S, Molema G, Bijzet J, et al. (2009) Time course of angiopoietin-2 release during experimental human endotoxemia and sepsis. Crit Care 13: R64.

21. Ong T, McClintock DE, Kallet RH, Ware LB, Matthay MA, et al. (2010) Ratio of angiopoietin-2 to angiopoietin-1 as a predictor of mortality in acute lung injury patients. Crit Care Med 38: 1845-1851. 
Citation: Lee JY, Miller EJ (2014) Angiopoietin-2: A Key to Understanding Sepsis and Its Pulmonary Sequelae? J Pulm Respir Med 4: 172. doi:10.4172/2161-105X.1000172

Page 6 of 8

22. van Nieuw Amerongen GP, Groeneveld AB (2010) A plethora of angiopoietin-2 effects during clinical sepsis. Crit Care 14: 166.

23. Calfee CS, Gallagher D, Abbott J, Thompson BT, Matthay MA; NHLBI ARDS Network (2012) Plasma angiopoietin-2 in clinical acute lung injury: prognostic and pathogenetic significance. Crit Care Med 40: 1731-1737.

24. Agrawal A, Matthay MA, Kangelaris KN, Stein J, Chu JC, et al. (2013) Plasma angiopoietin-2 predicts the onset of acute lung injury in critically ill patients. Am J Respir Crit Care Med 187: 736-742.

25. Choi JS, Kwak KA, Park MJ, Kim YH, Gil HW, et al. (2013) Ratio of angiopoietin-2 to angiopoietin-1 predicts mortality in acute lung injury induced by paraquat. Med Sci Monit 19: 28-33.

26. van der Heijden M, Pickkers P, van Nieuw Amerongen GP, van Hinsbergh VW, Bouw MP, et al. (2009) Circulating angiopoietin-2 levels in the course of septic shock: relation with fluid balance, pulmonary dysfunction and mortality. Intensive Care Med 35: 1567-1574.

27. Whitcomb DC, Muddana V, Langmead CJ, Houghton FD Jr, Guenther A, et al. (2010) Angiopoietin-2, a regulator of vascular permeability in inflammation, is associated with persistent organ failure in patients with acute pancreatitis from the United States and Germany. Am J Gastroenterol 105: 2287-2292.

28. Levy MM, Fink MP, Marshall JC, Abraham E, Angus D, et al. (2003) 2001 SCCM/ESICM/ACCP/ATS/SIS International Sepsis Definitions Conference. Intensive Care Med 29: 530 - 538 .

29. Martich GD, Boujoukos AJ, Suffredini AF (1993) Response of man to endotoxin Immunobiology 187: 403-416.

30. Lacour AG, Gervaix A, Zamora SA, Vadas L, Lombard PR, et al. (2001) Procalcitonin, IL-6, IL-8, IL-1 receptor antagonist and C-reactive protein as identificators of serious bacterial infections in children with fever without localising signs. Eur J Pediatr 160: 95-100.

31. Tracey K, Beutler B, Lowry SF, Merryweather J, Wolpe S, et al. (1986) Shock and tissue injury induced by recombinant human cachectin. Science 234: $470-$

32. Parrillo JE, Parker MM, Natanson C, Suffredini AF, Danner RL, et al. (1990) Septic shock in humans. Advances in the understanding of pathogenesis, cardiovascular dysfunction, and therapy. Ann Intern Med 113: 227-242.

33. Bone RC (1991) The pathogenesis of sepsis. Ann Intern Med 115: 457-469.

34. Vincent JL, Sakr Y, Sprung CL, Ranieri VM, Reinhart K, et al. (2006) Sepsis in European intensive care units: results of the SOAP study. Crit Care Med 34: 344-353.

35. Miller EJ, Cohen AB, Matthay MA (1996) Increased interleukin-8 concentrations in the pulmonary edema fluid of patients with acute respiratory distress syndrome from sepsis. Crit Care Med 24: 1448-1454.

36. Russell JA, Singer J, Bernard GR, Wheeler A, Fulkerson W, et al. (2000) Changing pattern of organ dysfunction in early human sepsis is related to mortality. Crit Care Med 28: 3405-3411.

37. Friedman G, De Backer D, Shahla M, Vincent JL (1998) Oxygen supply dependency can characterize septic shock. Intensive Care Med 24: 118-123.

38. Vincent JL (1998) Cardiovascular alterations in septic shock. J Antimicrob Chemother 41 Suppl A: 9-15.

39. Bernard GR, Wheeler AP, Russell JA, Schein R, Summer WR, et al. (1997) The effects of ibuprofen on the physiology and survival of patients with sepsis. The Ibuprofen in Sepsis Study Group. N Engl J Med 336: 912-918.

40. Hebert PC, Drummond AJ, Singer J, Bernard GR, Russell JA (1993) A simple multiple system organ failure scoring system predicts mortality of patients who have sepsis syndrome. Chest 104: 230-235.

41. Wallin TR, Hern HG, Frazee BW (2008) Community-associated methicillinresistant Staphylococcus aureus. Emerg Med Clin North Am 26: 431-455, ix.

42. Levy ML, Le Jeune I, Woodhead MA, Macfarlaned JT, Lim WS; British Thoracic Society Community Acquired Pneumonia in Adults Guideline Group (2010) Primary care summary of the British Thoracic Society Guidelines for the management of community acquired pneumonia in adults: 2009 update. Endorsed by the Royal College of General Practitioners and the Primary Care Respiratory Society UK. Prim Care Respir J 19: 21-27.

43. White L, Mirrani G, Grover M, Rollason J, Malin A, et al. (2012) Outcomes of Pseudomonas eradication therapy in patients with non-cystic fibrosis bronchiectasis. Respir Med 106: 356-360.
44. Hui DS (2005) An overview on severe acute respiratory syndrome (SARS) Monaldi Arch Chest Dis 63: 149-157.

45. Fechner H, Pinkert S, Geisler A, Poller W, Kurreck J (2011) Pharmacological and biological antiviral therapeutics for cardiac coxsackievirus infections. Molecules 16: 8475-8503.

46. Gibbert K, Schlaak JF, Yang D, Dittmer U (2013) IFN-Ît subtypes: distinct biological activities in anti-viral therapy. Br J Pharmacol 168: 1048-1058.

47. Fink JN (2000) Therapy of allergic bronchopulmonary aspergillosis. Indian $J$ Chest Dis Allied Sci 42: 221-224.

48. Baughman RP, Lower EE (2005) Fungal infections as a complication of therapy for sarcoidosis. QJM 98: 451-456.

49. Hayes D Jr, Murphy BS, Lynch JE, Feola DJ (2010) Aerosolized amphotericin for the treatment of allergic bronchopulmonary aspergillosis. Pediatr Pulmono 45: $1145-1148$

50. Leaper D (2006) Effects of local and systemic warming on postoperative infections. Surg Infect (Larchmt) 7 Suppl 2: S101-103.

51. Cheung KP, Taylor KR, Jameson JM (2012) Immunomodulation at epithelia sites by obesity and metabolic disease. Immunol Res 52: 182-199.

52. Pukstad BS, Ryan L, Flo TH, Stenvik J, Moseley R, et al. (2010) Non-healing is associated with persistent stimulation of the innate immune response in chronic venous leg ulcers. J Dermatol Sci 59: 115-122.

53. Stalker AL (1970) The microcirculation in shock. J Clin Pathol Suppl (R Col Pathol) 4: 10-15.

54. Lehr HA, Bittinger F, Kirkpatrick CJ (2000) Microcirculatory dysfunction in sepsis: a pathogenetic basis for therapy? J Pathol 190: 373-386.

55. Vincent JL, De Backer D (2005) Microvascular dysfunction as a cause of organ dysfunction in severe sepsis. Crit Care 9 Suppl 4: S9-12.

56. Vallet B (2002) Endothelial cell dysfunction and abnormal tissue perfusion. Crit Care Med 30: S229-234.

57. Skibsted S, Jones AE, Puskarich MA, Arnold R, Sherwin R, et al. (2013) Biomarkers of endothelial cell activation in early sepsis. Shock 39: 427-432.

58. Xu H, Ye X, Steinberg H, Liu SF (2010) Selective blockade of endothelial NFkappaB pathway differentially affects systemic inflammation and multiple organ dysfunction and injury in septic mice. J Pathol 220: 490-498.

59. Kerschen EJ, Fernandez JA, Cooley BC, Yang XV, Sood R, et al. (2007) Endotoxemia and sepsis mortality reduction by non-anticoagulant activated protein C. J Exp Med 204: 2439-2448.

60. Ye X, Ding J, Zhou X, Chen G, Liu SF (2008) Divergent roles of endothelia NF-kappaB in multiple organ injury and bacterial clearance in mouse models of sepsis. J Exp Med 205: 1303-1315.

61. Li X, Zheng Z, Mao Y, Ma X (2012) Unfractionated heparin promotes LPSinduced endothelial barrier dysfunction: a preliminary study on the roles of angiopoietin/Tie2 axis. Thromb Res 129: e223-228.

62. Ge L, Trujillo G1, Miller EJ2, Kew RR3 (2014) Circulating complexes of the vitamin $\mathrm{D}$ binding protein with $\mathrm{G}$-actin induce lung inflammation by targeting endothelial cells. Immunobiology 219: 198-207.

63. Giamarellos-Bourboulis EJ (2011) Angiopoietins in sepsis: biomarkers or effector molecules? Crit Care Med 39: 890-891.

64. van Meurs M, Kümpers P, Ligtenberg JJ, Meertens JH, Molema G, et al. (2009) Bench-to-bedside review: Angiopoietin signalling in critical illness - a future target? Crit Care 13: 207.

65. Davis S, Aldrich TH, Jones PF, Acheson A, Compton DL, et al. (1996) Isolation of angiopoietin-1, a ligand for the TIE2 receptor, by secretion-trap expression cloning. Cell 87: 1161-1169.

66. Valenzuela DM, Griffiths JA, Rojas J, Aldrich TH, Jones PF, et al. (1999) Angiopoietins 3 and 4: diverging gene counterparts in mice and humans. Proc Natl Acad Sci U S A 96: 1904-1909.

67. Peters KG, Kontos CD, Lin PC, Wong AL, Rao P, et al. (2004) Functiona significance of Tie2 signaling in the adult vasculature. Recent Prog Horm Res 59: 51-71.

68. Davis S, Papadopoulos N, Aldrich TH, Maisonpierre PC, Huang T, et al. (2003) Angiopoietins have distinct modular domains essential for receptor binding, dimerization and superclustering. Nat Struct Biol 10: 38-44. 
Citation: Lee JY, Miller EJ (2014) Angiopoietin-2: A Key to Understanding Sepsis and Its Pulmonary Sequelae? J Pulm Respir Med 4: 172. doi:10.4172/2161-105X.1000172

Page 7 of 8

69. Park HY, Hahm CR, Jeon K, Koh WJ, Suh GY, et al. (2012) Serum vascular endothelial growth factor and angiopoietin-2 are associated with the severity of systemic inflammation rather than the presence of hemoptysis in patients with inflammatory lung disease. Yonsei Med J 53: 369-376.

70. Lukasz A, Hellpap J, Horn R, Kielstein JT, David S, et al. (2008) Circulating angiopoietin-1 and angiopoietin-2 in critically ill patients: development and clinical application of two new immunoassays. Crit Care 12: R94.

71. van der Heijden M, van Nieuw Amerongen GP, Chedamni S, van Hinsbergh VW Johan Groeneveld AB (2009) The angiopoietin-Tie2 system as a therapeutic target in sepsis and acute lung injury. Expert Opin Ther Targets 13: 39-53.

72. van der Heijden M, van Nieuw Amerongen GP, van Hinsbergh VW, Groeneveld AB (2010) The interaction of soluble Tie2 with angiopoietins and pulmonary vascular permeability in septic and nonseptic critically ill patients. Shock 33 263-268

73. Ebihara I, Hirayama K, Nagai M, Kakita T, Sakai K, et al. (2011) Angiopoietin balance in septic shock patients with acute lung injury: effect of direct hemoperfusion with polymyxin B-immobilized fiber. Ther Apher Dial 15: 349354.

74. Rondaij MG, Bierings R, Kragt A, van Mourik JA, Voorberg J (2006) Dynamics and plasticity of Weibel-Palade bodies in endothelial cells. Arterioscler Thromb Vasc Biol 26: 1002 - 1007.

75. Lowenstein CJ, Morrell CN, Yamakuchi M (2005) Regulation of Weibel-Palade body exocytosis. Trends Cardiovasc Med 15: 302-308.

76. Wagner DD, Olmsted JB, Marder VJ (1982) Immunolocalization of von Willebrand protein in Weibel-Palade bodies of human endothelial cells. J Cell Biol 95: 355-360.

77. Russell FD, Skepper JN, Davenport AP (1998) Evidence using immunoelectron microscopy for regulated and constitutive pathways in the transport and release of endothelin. J Cardiovasc Pharmacol 31: 424-430.

78. Utgaard JO, Jahnsen FL, Bakka A, Brandtzaeg P, Haraldsen G (1998) Rapid secretion of prestored interleukin 8 from Weibel-Palade bodies of microvascular endothelial cells. J Exp Med 188: 1751-1756.

79. Bonfanti R, Furie BC, Furie B, Wagner DD (1989) PADGEM (GMP140) is a component of Weibel-Palade bodies of human endothelial cells. Blood 73 1109-1112.

80. Huber D, Cramer EM, Kaufmann JE, Meda P, Massé JM, et al. (2002) Tissuetype plasminogen activator (t-PA) is stored in Weibel-Palade bodies in human endothelial cells both in vitro and in vivo. Blood 99: 3637-3645.

81. Emeis JJ, van den Eijnden-Schrauwen $\mathrm{Y}$, van den Hoogen $\mathrm{CM}$, de Priester W, Westmuckett A, et al. (1997) An endothelial storage granule for tissue-type plasminogen activator. J Cell Biol 139: 245-256.

82. Hol J, Wilhelmsen L, Haraldsen G (2010) The murine IL-8 homologues KC MIP-2, and LIX are found in endothelial cytoplasmic granules but not in WeibelPalade bodies. J Leukoc Biol 87: 501-508.

83. van den Eijnden-Schrauwen $Y$, Atsma DE, Lupu F, de Vries RE, Kooistra T, et al. (1997) Involvement of calcium and $G$ proteins in the acute release of tissuetype plasminogen activator and von Willebrand factor from cultured human endothelial cells. Arterioscler Thromb Vasc Biol 17: 2177-2187.

84. Carley WW, Niedbala MJ, Gerritsen ME (1992) Isolation, cultivation, and partia characterization of microvascular endothelium derived from human lung. Am J Respir Cell Mol Biol 7: 620-630.

85. Ghitescu L, Robert M (2002) Diversity in unity: the biochemical composition of the endothelial cell surface varies between the vascular beds. Microsc Res Tech 57: 381-389.

86. Ofori-Acquah SF, King J, Voelkel N, Schaphorst KL, Stevens T (2008) Heterogeneity of barrier function in the lung reflects diversity in endothelial cell junctions. Microvasc Res 75: 391-402.

87. Klijn E, Den Uil CA, Bakker J, Ince C (2008) The heterogeneity of the microcirculation in critical illness. Clin Chest Med 29: 643-654, viii.

88. Thorin E, Shreeve SM (1998) Heterogeneity of vascular endothelial cells in normal and disease states. Pharmacol Ther 78: 155-166.

89. Weibe ER (2012) Fifty years of Weibel-Palade bodies: the discovery and early history of an enigmatic organelle of endothelial cells. J Thromb Haemost 10: 979-984.

90. Into T, Matsushita K (2007) Recognition of bacterial compounds by aortic endothelial cells activates Weibel-Palade body exocytosis. Inflammation and Regeneration 27: 112-116.

91. Lüttge M, Fulde M, Talay SR, Nerlich A, Rohde M, et al. (2012) Streptococcus pneumoniae induces exocytosis of Weibel-Palade bodies in pulmonary endothelial cells. Cell Microbiol 14: 210-225.

92. Siller-Matula JM, Schwameis M, Blann A, Mannhalter C, Jilma B (2011) Thrombin as a multi-functional enzyme. Focus on in vitro and in vivo effects. Thromb Haemost 106: 1020-1033.

93. Noubade R, del Rio R, McElvany B, Zachary JF, Millward JM, et al. (2008) von-Willebrand factor influences blood brain barrier permeability and brain inflammation in experimental allergic encephalomyelitis. Am J Pathol 173: 892 900

94. Ware LB, Eisner MD, Thompson BT, Parsons PE, Matthay MA (2004) Significance of von Willebrand factor in septic and nonseptic patients with acute lung injury. Am J Respir Crit Care Med 170: 766-772.

95. Pickkers P, Sprong T, Eijk Lv, Hoeven Hv, Smits P, et al. (2005) Vascular endothelial growth factor is increased during the first 48 hours of human septic shock and correlates with vascular permeability. Shock 24: 508-512.

96. Ricciuto DR, dos Santos CC, Hawkes M, Toltl LJ, Conroy AL, et al. (2011) Angiopoietin-1 and angiopoietin-2 as clinically informative prognostic biomarkers of morbidity and mortality in severe sepsis. Crit Care Med 39: 702 710.

97. Koutsostathis S, Tsaganos T, Lallos S, Georgitsi M, Roumeliotis L, et al. (2011) Early increase of serum angiopoietin-2 are associated with early progression to death in experimental injury. Cytokine 56: 817-822.

98. Siner JM, Bhandari V, Engle KM, Elias JA, Siegel MD (2009) Elevated serum angiopoietin 2 levels are associated with increased mortality in sepsis. Shock 31: $348-353$

99. Orfanos SE, Kotanidou A, Glynos C, Athanasiou C, Tsigkos S, et al. (2007) Angiopoietin-2 is increased in severe sepsis: correlation with inflammatory mediators. Crit Care Med 35: 199-206.

100.Davis JS, Yeo TW, Piera KA, Woodberry T, Celermajer DS, et al. (2010) Angiopoietin-2 is increased in sepsis and inversely associated with nitric oxide-dependent microvascular reactivity. Crit Care 14: R89.

101. Giuliano JS Jr, Tran K, Li FY, Shabanova V, Tala JA, et al. (2014) The tempora kinetics of circulating angiopoietin levels in children with sepsis. Pediatr Crit Care Med 15: e1-8.

102. Thurston G, Suri C, Smith K, McClain J, Sato TN, et al. (1999) Leakage resistant blood vessels in mice transgenically overexpressing angiopoietin-1. Science 286: 2511-2514.

103. Fiedler U, Reiss Y, Scharpfenecker M, Grunow V, Koidl S, et al. (2006) Angiopoietin-2 sensitizes endothelial cells to TNF-alpha and has a crucial role in the induction of inflammation. Nat Med 12: 235-239.

104. Benest AV, Kruse K, Savant S, Thomas M, Laib AM, et al (2013) Angiopoietin-2 is critical for cytokine-induced vascular leakage. PLoS One 8: e70459.

105. David S, Mukherjee A, Ghosh CC, Yano M, Khankin EV, et al. (2012) Angiopoietin-2 may contribute to multiple organ dysfunction and death in sepsis*. Crit Care Med 40: 3034-3041.

106.Ziegler T, Horstkotte J, Schwab C, Pfetsch V, Weinmann K, et al. (2013) Angiopoietin 2 mediates microvascular and hemodynamic alterations in sepsis. J Clin Invest .

107. Roviezzo F, Tsigkos S, Kotanidou A, Bucci M, Brancaleone V, et al. (2005) Angiopoietin-2 causes inflammation in vivo by promoting vascular leakage. $J$ Pharmacol Exp Ther 314: 738-744.

108. Parikh SM, Mammoto T, Schultz A, Yuan HT, Christiani D, et al. (2006) Excess circulating angiopoietin-2 may contribute to pulmonary vascular leak in sepsis in humans. PLoS Med 3: e46.

109. Lee JY, Linge HM, Ochani K, Lin K, Miller EJ (2013) Inhibition of Angiopoietin-2 (Ang-2) Exocytosis is Associated with Improved Pulmonary Function Following Gram-Positive Challenge. Shock 40 - Supplement 1: 32

110. Lomas-Neira J, Venet F, Chung CS, Thakkar R, Heffernan D, et al. (2014) Neutrophil-endothelial interactions mediate angiopoietin-2-associated pulmonary endothelial cell dysfunction in indirect acute lung injury in mice. Am J Respir Cell Mol Biol 50: 193-200.

111. Kuo MC, Patschan D, Patschan S, Cohen-Gould L, Park HC, et al. (2008) 
Citation: Lee JY, Miller EJ (2014) Angiopoietin-2: A Key to Understanding Sepsis and Its Pulmonary Sequelae? J Pulm Respir Med 4: 172. doi:10.4172/2161-105X.1000172

Page 8 of 8

Ischemia-induced exocytosis of Weibel-Palade bodies mobilizes stem cells. J Am Soc Nephrol 19: 2321-2330.

112. Into T, Kanno Y, Dohkan J, Nakashima M, Inomata M, et al. (2007) Pathogen recognition by Toll-like receptor 2 activates Weibel-Palade body exocytosis in human aortic endothelial cells. J Biol Chem 282: 8134-8141.

113. Zupancic G, Ogden D, Magnus CJ, Wheeler-Jones C, Carter TD (2002) Differential exocytosis from human endothelial cells evoked by high intracellular $\mathrm{Ca}(2+)$ concentration. J Physiol 544: 741-755.

114. van der Heijden M, van Nieuw Amerongen GP, van Bezu J, Paul MA Groeneveld AB, et al. (2011) Opposing effects of the angiopoietins on the thrombin-induced permeability of human pulmonary microvascular endothelial cells. PLoS One 6: e23448.

115. Minhas N, Xue M, Fukudome K, Jackson CJ (2010) Activated protein C utilizes the angiopoietin/Tie2 axis to promote endothelial barrier function. FASEB J 24: 873-881.

116. Eklund L, Olsen BR (2006) Tie receptors and their angiopoietin ligands are context-dependent regulators of vascular remodeling. Exp Cell Res 312: 630641.

117. Fiedler U, Scharpfenecker M, Koidl S, Hegen A, Grunow V, et al. (2004) The Tie-2 ligand angiopoietin-2 is stored in and rapidly released upon stimulation from endothelial cell Weibel-Palade bodies. Blood 103: 4150-4156.

118. Harfouche R, Hussain SN (2006) Signaling and regulation of endothelial cel survival by angiopoietin-2. Am J Physiol Heart Circ Physiol 291: H1635-1645.

119. Methe H, Balcells M, Alegret Mdel C, Santacana M, Molins B, et al. (2007) Vascular bed origin dictates flow pattern regulation of endothelial adhesion molecule expression. Am J Physiol Heart Circ Physiol 292: H2167-2175.

120. Armulik A, Abramsson A, Betsholtz C (2005) Endothelial/pericyte interactions. Circ Res 97: 512-523.

121. Cai J, Kehoe O, Smith GM, Hykin P, Boulton ME (2008) The angiopoietin/Tie2 system regulates pericyte survival and recruitment in diabetic retinopathy. Invest Ophthalmol Vis Sci 49: 2163-2171.

122. Bergers G, Song S (2005) The role of pericytes in blood-vessel formation and maintenance. Neuro Oncol 7: 452-464.

123. Phelps ED, Updike DL, Bullen EC, Grammas P, Howard EW (2006) Transcriptional and posttranscriptional regulation of angiopoietin-2 expression mediated by IGF and PDGF in vascular smooth muscle cells. Am J Physio Cell Physiol 290: C352-361.

124. Anwar KN, Fazal F, Malik AB, Rahman A (2004) RhoA/Rho-Associated Kinase Pathway Selectively Regulates Thrombin-Induced Intercellular Adhesion Molecule-1 Expression in Endothelial Cells via Activation of IkB Kinase b and Phosphorylation of RelA/p65. J Immunol 173: 6965-6972.

125. Murdoch C, Tazzyman S, Webster S, Lewis CE (2007) Expression of Tie-2 by human monocytes and their responses to angiopoietin-2. J Immunol 178 : 7405-7411.

126. van Hinsbergh VW (2012) Endothelium--role in regulation of coagulation and inflammation. Semin Immunopathol 34: 93-106.

127. Bhandari V, Choo-Wing R, Lee CG, Zhu Z, Nedrelow JH, et al. (2006) Hyperoxia causes angiopoietin 2-mediated acute lung injury and necrotic cell death. Nat Med 12: 1286-1293.
28. Schrobback K, Klein TJ, Crawford R, Upton Z, Malda J, et al. (2012) Effects of oxygen and culture system on in vitro propagation and redifferentiation of osteoarthritic human articular chondrocytes. Cell Tissue Res 347: 649-663.

129. Baumgardner JE, Otto CM (2003) In vitro intermittent hypoxia: challenges for creating hypoxia in cell culture. Respir Physiol Neurobiol 136: 131-139.

130. Powers DE, Millman JR, Bonner-Weir S, Rappel MJ, Colton CK (2010) Accurate control of oxygen level in cells during culture on silicone rubber membranes with application to stem cell differentiation. Biotechnol Prog 26 805-818

131. McLimans WF, Crouse EJ, Tunnah KV Moore GE (1968) Kinetics of gas diffusion in mammalian cell culture systems. I Experimental Biotechnology and Bioengineering 10: 725-740

132. Metzen E, Wolff M, Fandrey J, Jelkmann W (1995) Pericellular PO2 and O2 consumption in monolayer cell cultures. Respir Physiol 100: 101-106.

133. Pettersen EO, Larsen LH, Ramsing NB, Ebbesen P (2005) Pericellular oxygen depletion during ordinary tissue culturing, measured with oxygen microsensors. Cell Prolif 38: 257-267.

134. Stevens KM (1965) Oxygen requirements for liver cells in vitro. Nature 206 199

135. Goerge T, Niemeyer A, Rogge P, Ossig R, Oberleithner H, et al. (2002) Secretion pores in human endothelial cells during acute hypoxia. J Membr Biol 187: 203-211.

136. Hughes P, Marshall D, Reid Y, Parkes H, Gelber C (2007) The costs of using unauthenticated, over-passaged cell lines: how much more data do we need? Biotechniques 43: 575, 577-578, 581-2 passim

137. Carrillo-Sepúlveda MA, Barreto-Chaves ML (2010) Phenotypic modulation of cultured vascular smooth muscle cells: a functional analysis focusing on MLC and ERK1/2 phosphorylation. Mol Cell Biochem 341: 279-289.

138. Appleby LJ, Nausch N, Midzi N, Mduluza T, Allen JE, et al. (2013) Sources of heterogeneity in human monocyte subsets. Immunol Lett 152: 32-41.

139. Schutzer WE, Beard DR, Reed JF, Mader SL (2011) Characterization of clonal vascular smooth muscle cell lines derived from young and old Fischer 344 rats. In Vitro Cell Dev Biol Anim 47: 445-450.

140. Miebach S, Grau S, Hummel V, Rieckmann P, Tonn JC, et al. (2006) Isolation and culture of microvascular endothelial cells from gliomas of different WHO grades. J Neurooncol 76: 39-48. 